\title{
ASSESSMENT OF AIR POLLUTION FROM TEHRAN-MEHRABAD AIRPORT, IRAN
}

\author{
G. BADALIANS GHOLIKANDI ${ }^{1}$, M. LASHKARI ${ }^{2}$, H.R. ORUMIEH ${ }^{3}$, H.R. TASHAOUIE ${ }^{4} \&$ S. HADDADI $^{5}$ \\ ${ }^{1}$ Power and Water University of Technology (PWUT), Tehran, Iran. \\ ${ }^{2}$ Tehran Water and Wastewater Company (TWWC), Tehran, Iran. \\ ${ }^{3}$ Pars Arianab, Consulting Engineers, Esfahan, Iran. \\ ${ }^{4}$ Faculty of Hygienic Engineering, University of Esfahan, Iran. \\ ${ }^{5}$ Faculty of Environment, University of Tehran/WRI, Tehran, Iran.
}

\begin{abstract}
Development of airports has brought about substantial socioeconomic, environmental and welfare benefits for the sustainable development of countries. Nevertheless, environmental impacts of aircraft emissions and their control should not be underestimated. In recent years, the growing air traffic has led to increment of air pollution in this sector of transportation which is expected to affect local and global air quality. Due to high importance of this subject, numerous studies have been conducted in this field; however, these studies have focused mostly on the effects of this kind of pollution on the upper atmospheric layers and few have taken the earth's layer and urban areas into account. This article aims to assess the rate of gas and particulate emission during airplanes' landing/take off cycle and the effects of atmospheric currents on their distribution and spreading in the TehranMehrabad Airport, Iran. Two pollutant clusters are subjected in this study; cluster one including particulates less than $2.5 \mu \mathrm{m}\left(\mathrm{PM}_{25}\right)$ and cluster two including gas pollutants such as $\mathrm{SO}_{2}, \mathrm{CO}_{2}, \mathrm{~N}_{2} \mathrm{O}, \mathrm{NO}_{\mathrm{X}}$ and $\mathrm{CO}$. Distribution rate of the first cluster pollutant is estimated using First Order Approximation Method (FAO) published by Federal Aviation Administration and Smoke Number (SN) of each engine. The amount of the latter cluster is calculated using method stated by Committee on Aviation Environmental Protection (CAEP). Therefore, approximate rate of pollution distribution in the local area is calculated separately for each cluster, considering the approximate annual number of landings and take-offs and the types of aircrafts in Tehran-Mehrabad Airport. Finally, automobile equivalent of fuel consumption by each aircraft in an ordinary day is estimated.

Keywords: air pollution, gas emissions, landing/take off cycle, Mehrabad Airport, PM 2.5 .
\end{abstract}

\section{INTRODUCTION}

Access to air services has reduced the time and costs of transporting goods and passengers which allows wider access to markets, and thus contributing to long-term economic development [1]. Air transport plays a key role in the promotion of trade, tourism and economic growth, and long-term sustainable growth of a country [2]. It is now accepted as a fundamental pillar of our global society, indispensable to our daily lives as medicine and telecommunications, and essential for social progress and economic prosperity [3]. On the other side, like most human activities, air transport has an impact on the environment. The industry fully recognizes its responsibility in this regard and is determined to accelerate action aimed at mitigating its environmental impact - preserving and enhancing its economic and social benefits at the same time. For example:

- Aircraft entering today's fleets are 20 decibels (dB) quieter than comparable aircraft 40 years ago. This corresponds to a reduction in noise annoyance of $75 \%$.

- A further $50 \%$ reduction in noise during take-off and landing $(-10 \mathrm{~dB})$ is expected by 2020 .

- Aircrafts entering today's fleets are 70\% more fuel-efficient than they were 40 years ago. This corresponds to a reduction of $75 \%$ in noise annoyance due to fuel-efficiency?.

- Research programs aim to achieve a further $50 \%$ fuel saving and an $80 \%$ reduction in oxides of nitrogen by 2020.

- Enhancements in air traffic management have the potential to reduce fuel burn by $6-12 \%$, while operational improvements can bring an additional 2-6\% fuel saving [3, 4].

(C) 2010 WIT Press, www.witpress.com

ISSN: 1743-7601 (paper format), ISSN: 1743-761X (online), http://journals.witpress.com

DOI: $10.2495 /$ SDP-V5-N2-185-191 
The size of the world's fleet has increased constantly over the past decades and is expected to do so in the future. In the last decade air traffic has increased dramatically: 47\% between 1991 and 2000 [5]. Global passenger air travel, as measured in revenue passenger-km (RPK), is projected to grow by about $5 \%$ per year between 1990 and 2015, whereas total aviation fuel use is projected to increase by $3 \%$ per year, over the same period, and aircraft efficiency is simultaneously improved [6]. Airbus has predicted that worldwide air travel would nearly triple during the next 20 years reaching 9 trillion RPKs by 2023 with an annual growth rate of $5.3 \%$ at average. This growth rate means that in 20 years time, air travel would be growing by about 390 billion RPKs each year [1]. These increases likely lead to increases in environmental impacts too.

Unlike most transportation modes, aircraft travel long distances at a variety of altitudes, generating emissions that have the potential to impact air quality in the local, regional and global environments [7]. In spite of substantial improvements in engine technology, aircraft operations result in the emission of gaseous and particle effluents, including carbon dioxide, water, hydrocarbons, carbon monoxide, nitrogen oxides, sulphur, soot, etc. [2]. The US Environmental Protection Agency (EPA) estimated that emission of volatile organic carbon (VOC) by airports, i.e. aircrafts and ground support equipments in 1999 has increased by more than $80 \%$ as compared to 1970 . Moreover, nitrogen oxide $\left(\mathrm{NO}_{\mathrm{X}}\right)$ emission has doubled during that same period of time. Airport emissions now make up about $2 \%$ of total non-road emissions [5].

In recent years, several studies assessed atmospheric impacts of these emissions, however, mostly focused on the impacts on the upper atmospheric layers and fewer have taken the earth's layer and urban areas into account.

Environmental impacts of aircrafts' gaseous and particulate emissions addressed to in previous studies are global climate change, noise and community impacts, local air quality in the vicinity of airports, damage to stratospheric ozone layer, acid rain, and perhaps radiative forcing. Emissions of $\mathrm{NO}_{\mathrm{X}}, \mathrm{CO}, \mathrm{HC}_{\mathrm{S}}$ and particles are relevant to local air quality issues and $\mathrm{CO}_{2}, \mathrm{H}_{2} \mathrm{O}, \mathrm{NO}_{\mathrm{X}}, \mathrm{SO}_{\mathrm{X}}$ and particles are of most concern in terms of climate perturbation [7-10]. In addition to aircraft emissions, other emissions emanating from the airport environment occur during the handling of aircraft. Ground support equipment (GSE) encompasses all vehicles and machinery needed to service the aircraft on the ground between arrival and departure events [11].

In competitive markets when there have been multiple choices for airport placement with the same price and number of travel (benefits), selection is made based on availability to save and time and cost [12]. Mehrabad Airport is situated in an appropriate location from this point of view as the rapidly growing population and development of Tehran City have placed the airport inside the urban area. Therefore access to the airport is possible at low costs, although it may cause special environmental impacts that should not be underestimated.

By contrast, traffic volume makes difficult availability to the airport and lowers its popularity. Then, many airport carriers prefer a 20-30 mile distance between airport and city. Taking into account the volume of passenger traffic and jobs, the best decision can be made. To resolve these problems, the second Tehran airport (Imam Khomeini International Airport), located in the southwestern of the city, was established [12].

As mentioned previously, several studies have assessed airport emissions. Schürmann and coworkers investigated the impact of $\mathrm{NO}_{\mathrm{X}}, \mathrm{CO}$ and $\mathrm{VOC}$ emissions on the air quality of Zurich airport. Results showed $\mathrm{CO}$ concentrations in the vicinity of the terminals were found to be highly dependent on aircraft movement, whereas NO concentrations were dominated by emissions from ground support vehicles [11]. The impact of aircraft emissions was quantified on regional air quality of HartsfieldJackson Atlanta International Airport, in other study [5]. An air dispersion model, ADMS-Urban, was used to estimate temporal and spatial contributions to $\mathrm{NO}_{\mathrm{X}}$ concentrations from aircraft and 
traffic around Heathrow airport in West London [13]. In Iran, no study has been conducted on local air pollution from the aviation sector, nevertheless air pollution is the biggest environmental problem of Iran, especially in the capital city of Tehran. This is the first time that emissions from aircrafts in Iran are subjected as a case study. To mitigate environmental impacts, local authorities are required to undertake the contribution of various sources of air pollution, such as airports.

\section{MATERIAL AND METHODS}

\subsection{Study area}

Mehrabad Airport (THR) is an airport in Tehran, Iran, situated on $35^{\circ} 41^{\prime} 23^{\prime \prime} \mathrm{N}$ longitude and $51^{\circ}$ $18^{\prime} 57^{\prime \prime}$ E latitude [14]. It was the primary airport of Tehran located on west of this city but in recent years has been replaced by Imam Khomeini International Airport (IKA) - located at a further distance from the city - in all of its international flights except flights to Saudi Arabia [15]. Flights can only be carried out under VFR (Instrument Meteorological Conditions) or IFR (Instrument Flight Rules). Switch of international flights to IKA was finished in 2004 and has gradual starting with flights to countries bordering the Persian Gulf. All international flights have now been moved to IKA except flights to Saudi Arabia [16].

\subsection{Methods}

In this research the effect of two pollutant clusters, including particulates less than $2.5 \mu \mathrm{m}\left(\mathrm{PM}_{2.5}\right)$ and gas pollutants such as $\mathrm{SO}_{2}, \mathrm{CO}_{2}, \mathrm{~N}_{2} \mathrm{O}, \mathrm{NO}_{\mathrm{X}}$ and $\mathrm{CO}$, on the local area are assessed. $\mathrm{PM}_{2.5}$ is estimated using First Order Approximation Method (FAO) proposed by Federal Aviation Administration in which distribution rate is function of Smoke Number (SN) and fuel flow [17, 18]:

$$
\mathrm{EI}=0.6 \times(\mathrm{SN})^{1.8} \times(\mathrm{FF})
$$

where $\mathrm{EI}=$ emission index: $\mathrm{mg}$ of $\mathrm{PM}$ emitted per second per engine type; $\mathrm{SN}=$ smoke number, the dimensionless term quantifying smoke emissions; $\mathrm{FF}=$ fuel flow rate in $\mathrm{kg} / \mathrm{s}$.

To measure smoke level, smoke particles are trapped in a filter as mass of exhaust per unit area of filter and then it is compared to standard filters. The reference emissions landing and take-off (LTO) cycle consists of four modal phases approach, taxi/idle, take-off and climb which respectively, correspond to 4, 26, 0.7, and 2.2 min of time-in-mode, and 30, 7, 100 and $85 \%$ of rated thrust [7]. For most aircrafts SN is only measured for the take-off mode. SN for other modes can be estimated using following equations [5].

$$
\begin{gathered}
\mathrm{SN}_{\text {Climb-out }}=0.86 \times \mathrm{SN}_{\text {Take-off }} \\
\mathrm{SN}_{\text {Approach }}=0.51 \times \mathrm{SN}_{\text {Take-off }} \\
\mathrm{SN}_{\text {Idle }}=0.41 \times \mathrm{SN}_{\text {Take-off }}
\end{gathered}
$$

Gas emissions are estimated using their distribution rate during every LTO cycle.

International Civil Aviation Organization (ICAO) has published rates of pollutants distribution and fuel consumption for various aircraft engines (Table1). These data have been used to estimate fuel consumption and gaseous pollutants from Mehrabad Airport fleet, as stated in eqns (5) and (6) [19].

$$
\text { LTO Emissions }=\text { Number of } \mathrm{LTO}_{2} \times \text { Emission factor }_{\text {LTO }}
$$


Table 1: Pollutants distribution and fuel consumption rates as $\mathrm{kg}$ per LTO cycle $(\mathrm{kg} / \mathrm{LTO})$.

\begin{tabular}{lrrrrrr}
\hline Fleet & \multicolumn{1}{c}{$\mathrm{CO}_{2}$} & $\mathrm{~N}_{2} \mathrm{O}$ & $\mathrm{NO}_{\mathrm{X}}$ & $\mathrm{CO}$ & $\mathrm{SO}_{2}$ & Fuel \\
\hline A300 & 5,450 & 0.2 & 25.86 & 14.8 & 1.72 & 1,720 \\
$\mathrm{~A} 310$ & 4,760 & 0.2 & 19.46 & 28.3 & 1.51 & 1,510 \\
B747 & 11,370 & 0.4 & 49.52 & 79.78 & 3.6 & 3,600 \\
B737 & 2,460 & 0.1 & 9.12 & 8 & 0.78 & 780 \\
B727 & 4,610 & 0.1 & 11.97 & 27.16 & 1.46 & 1,460 \\
B707 & 5,890 & 0.2 & 10.96 & 92.37 & 1.86 & 1,860 \\
TU-154 & 5,960 & 0.2 & 12 & 82.88 & 1.89 & 1,890 \\
Fokker & 2,390 & 0.1 & 5.57 & 13.84 & 0.76 & 760 \\
Others & 2,880 & 0.1 & 10.66 & 10.22 & 0.91 & 910 \\
\hline
\end{tabular}

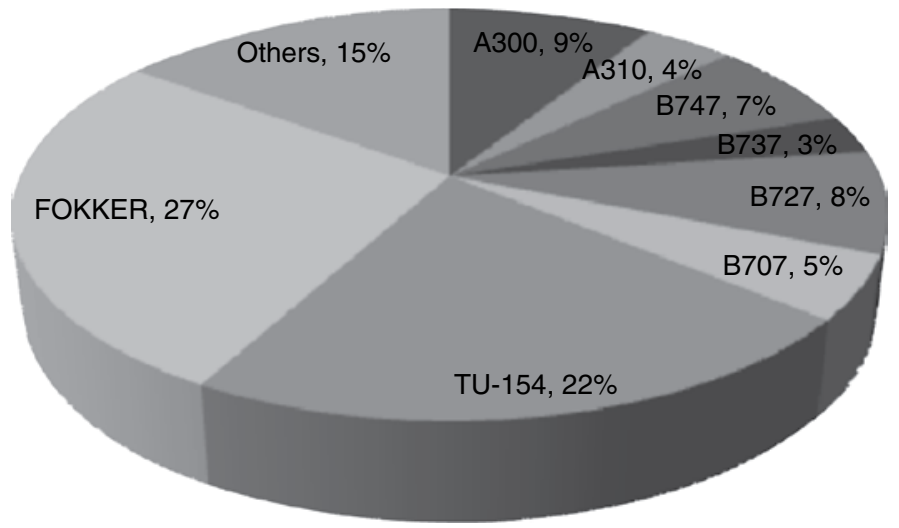

Figure 1: LTO percentage of Mehrabad Airport fleets.

Table 2: Mehrabad airport emissions and fuel consumptions during LTO cycles.

\begin{tabular}{lcclccc}
\hline Unit & $\mathrm{CO}_{2}$ & $\mathrm{~N}_{2} \mathrm{O}$ & $\mathrm{NO}_{\mathrm{X}}$ & $\mathrm{CO}$ & $\mathrm{SO}_{2}$ & Fuel \\
\hline ton/year & 506,264 & 17.71 & $1,550.373$ & $4,244.163$ & 160.369 & 160,369 \\
kg/day & $1,387,024.7$ & 48.52 & $4,247.6$ & $11,627.84$ & 439.367 & 439,367 \\
\hline
\end{tabular}

\section{RESULTS}

Almost 110,000 LTO cycles occurs every year in Mehrabad Airport. Figure 1 shows share of each fleet. Formulas and methods mentioned above were applied to estimate aircraft emissions. Calculations revealed an annual distribution of 160 tons for $\mathrm{PM}_{2.5}$ and 506,000 tons in case of $\mathrm{CO}_{2}$ in the airport area. In these LTO cycles, fuel is consumed at the rate of 160 tons per year leading to total annual emissions of 506,264, 18, 1,550, 4,244 and 160 tones of $\mathrm{CO}_{2}, \mathrm{~N}_{2} \mathrm{O}, \mathrm{NO}_{\mathrm{X}}$, $\mathrm{CO}$ and $\mathrm{SO}_{2}$, respectively, as delineated in Table 2 ( $\mathrm{SN}$ applied for particulate estimations have been demonstrated in Fig. 2).

The approximate average aviation spirit consumption is 2,100 liters per LTO resulting in annual burning of 230 million liters fuel in the airport. Total emissions by air traffic in the airport were 


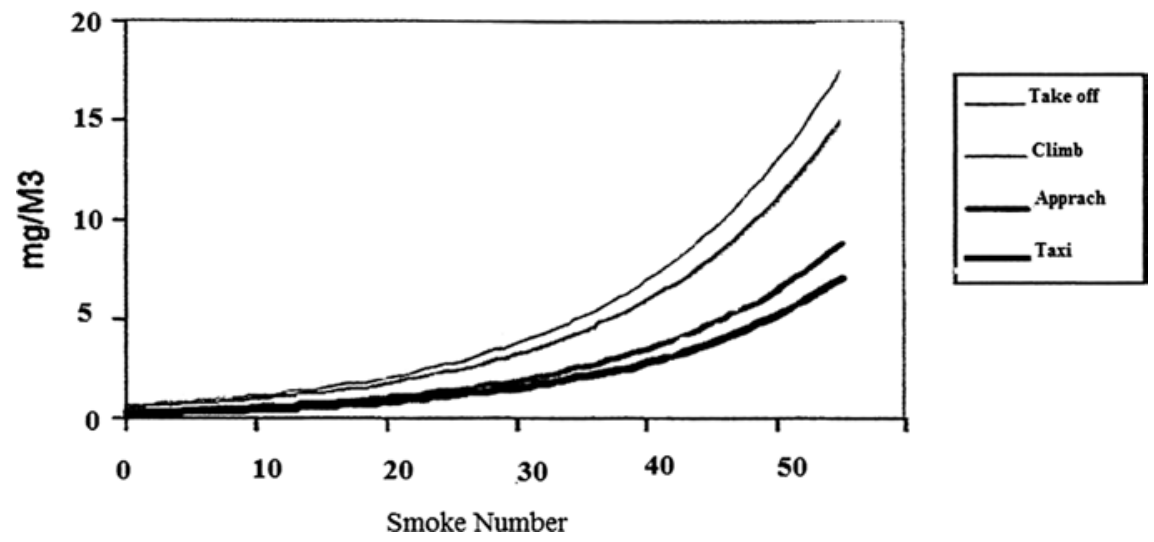

Figure 2: Smoke number in different flight modes [20].

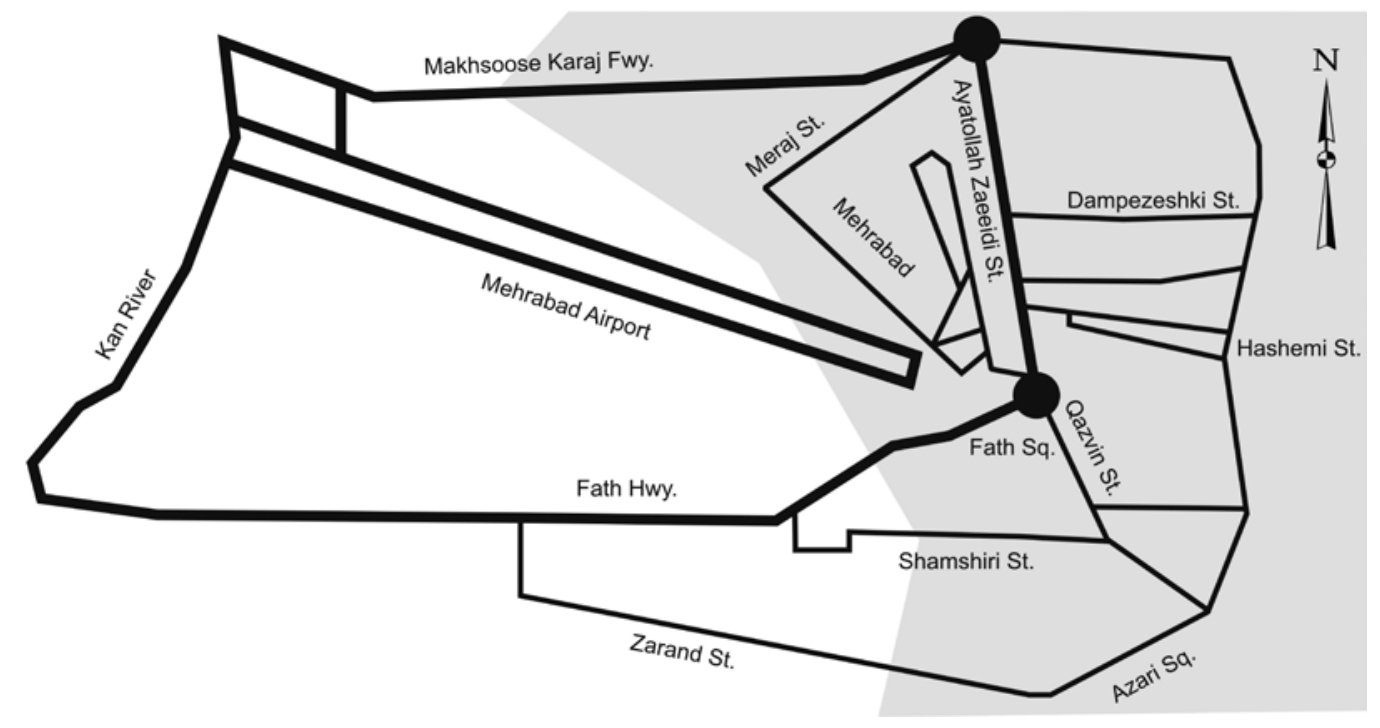

Figure 3: Pollution rate of municipal district no. 9 of Tehran [20].

calculated using number of LTO cycles and aircraft fleets. Assuming the fuel consumption of an automobile about 7 liter per day, annual automobile equivalent of fuel burned in this airport is about 90,000 .

Because of the airport being located near Tehran city, passengers get stuck in Tehran traffic jam increasing the traffic and related air pollution. So beside aircraft emissions, pollutions by cars delivering passengers to the airport need to be taken into consideration as well; annual numbers of 4.5 million passengers travel from this airport. These pollution sources locate in wind direction flowing amount of pollution toward the city.

Figure 3 illustrates the 10 day average of $\mathrm{CO}$, the most important aircraft pollutant, in the municipal district no. 9 of Tehran in which ground transportation is considered as a significant cause of 
pollution as well. As shown, the prevailing wind directs large part of pollution toward the city. In 2007-2008, 1.5 million trips were made daily, 1.25 million of which pertained to residents and 250,000 to non-residents [21].

According to statistics issued by Urban Planning and Research Center of Teheran in 2005, 70 tons of particle matter, 2 tons of lead, 3,560 tons of CO, 1,260 tons of non-methane volatile organic matters, 285 tons of $\mathrm{SO}_{\mathrm{X}}$, and 452 tons of $\mathrm{NO}_{\mathrm{X}}$ are annually released to Tehran air. Among various pollution sources, cars are responsible for $75 \%$ of particulates, $95 \%$ of $\mathrm{CO}$ and $60 \%$ of $\mathrm{NO}_{\mathrm{X}}$, whilst industries are associated with $75 \%$ of organic matter, $55 \%$ of $\mathrm{SO}_{2}$ and $46 \%$ of green house gases [22].

Comparison between pollutants released to Tehran air and those emitted by Mehrabad airport demonstrates the importance of airport pollution which is even more than total air pollutants in Tehran.

\section{CONCLUSION}

This paper presents the estimation of aircraft emissions, $\mathrm{PM}_{2.5}$ and gases pollutants, in Mehrabad Airport. Results demonstrate annually distribution rate of 160 tons of $\mathrm{PM}_{2.5}$ and nearly 506,000 tons of $\mathrm{CO}_{2}$ in vicinity of the airport. Furthermore, traveling by the aircraft causes the flow of automobiles taking passengers to this place which is an additional cause of traffic and air pollution. This indicates the indirect role of airport in producing air pollution. Moreover, Mehrabad airport is located in the west of the city where the prevailing wind directs aircraft emissions and other related pollution toward the city which, considering the potential for development of Imam Khomeini airport, stresses the importance of traffic reduction in the vicinity of this airport. Not paying attention to these effects would bring about irremediable environmental damage. In addition, it is necessary to understand better the effects of pollution on the health of children and other vulnerable members of society.

\section{REFERENCES}

[1] ICAO/ATG, Maximizing Civil Aviation Economic Contribution, Challenges and Potential, Montreal, Canada, 2005.

[2] Civil Aviation Administration, Draft National Aviation Policy, 2007.

[3] ATAG, The Economic and Social Benefits of Air Transport, Air Transport Action Group, 2005.

[4] ATAG, The Economic and Social Benefits of Air Transport, Air Transport Action Group, 2008.

[5] Unal, A., et al., Airport related emissions and impacts on air quality: application to the Atlanta International Airport. Atmospheric Environment, 39(32), pp. 5787-5798, 2005.

[6] IPPC, How are aviation emissions projected to grow in the future? http://www.grida.no/ climate/ipcc/aviation/005.htm, 2003.

[7] ICAO, Committee on Aviation Environmental Protection (CAEP). Airport Air Quality Guidance Manual, 2007. Working Paper, Seventh Meeting.

[8] Peace, H., et al., Identifying the contribution of different airport related sources to local urban air quality. Environmental Modelling \& Software, 21, pp. 532-538, 2006.

[9] Rogers, H.L., et al., The impacts of aviation on the atmosphere. The Aeronautical Journal, 104(1064), pp. 521-546, 2002.

[10] Miller, B., Aircraft Emissions Reductions through Improved Operational Performance. Thesis for Master of Science in Technology and Policy, Massachusetts Institute of Technology, 2001.

[11] IMK-IFU, F.K.G., The Impact of NOX, CO and VOC Emissions on the Air Quality of Zurich Airport. Institute of Meteorology and Climate Research, Atmospheric Environmental Research, 2005. 
[12] Gillen, D., Airport Economic, Policy and Management: The European Union, University of British Columbia, 2006.

[13] Farias, F. \& ApSimon, H., Relative contributions from traffic and aircraft NOx emissions to exposure in West London. Environmental Modelling \& Software, 21(4), pp. 477-485. 2006.

[14] THR/OIII, M.I.A., http://www.convertunits.com/distance/airport/THR.

[15] wikipedia, http://en.wikipedia.org/wiki/Mehrabad_Airport.

[16] wapedia, http://wapedia.mobi/en/Mehrabad_International_Airport.

[17] FAA, Fuel Venting and Exhaust Emission Requirements for Turbine Engine Powered Airplanes, Advisory Circular, 2003.

[18] Wayson, R.L., et al., Derivation of a First Order Approximation of Particulate Matter from Aircraft, Federal Aviation Administration, Paper \# 69970.

[19] Allyn, D., IPCC-National Greenhouse Gas Inventory Process (NGGIP). Methods for assessing Aviation Emissions, ICAO Colloquium on Aviation Emission with Exhibition, 2007.

[20] Ebrahimi, M., Jahangirian, A., Mehrabad Airport Air Impact Assessment for Regional Air Quality, Islamic Azad University: Mashhad, Iran, 2007.

[21] Mojabi, S.M., Role of Pollutant Sources in Tehran, Iran Daily, Tehran Urban Planning and Studies, 2009.

[22] TUPC, Scientific study of Tehran air pollution, Naft e Pars, 2005. 